\title{
Factor XIII crosslinked adhesive chitosan hydrogels
}

\author{
Ingrid Berg ${ }^{\mathrm{a}, \neq}$, Riccardo Rizzo ${ }^{\mathrm{a}, \neq}$, Mihyun Lee $^{\mathrm{a}, \ddagger}$, Qun Ren ${ }^{\mathrm{b}}$, Nicolas Broguiere ${ }^{\mathrm{a}, \mathrm{c}}$ and Marcy Zenobi- \\ Wong, $^{\text {a, }}$ \\ ${ }^{a}$ Tissue Engineering + Biofabrication Laboratory, Department of Health Sciences \& Technology, ETH Zürich, Otto- \\ Stern-Weg 7, 8093 Zürich, Switzerland \\ 'baboratory for Biointerfaces, Empa, Swiss Federal Laboratories for Materials Science and Technology, \\ Lerchenfeldstrasse 5, 9014 St. Gallen, Switzerland \\ 'Laboratory of Stem Cell Bioengineering, School of Life Sciences and School of Engineering, EPFL, Lausanne, 1015 \\ Vaud, Switzerland
}

\section{Table of Contents}

Materials and methods..............................................................

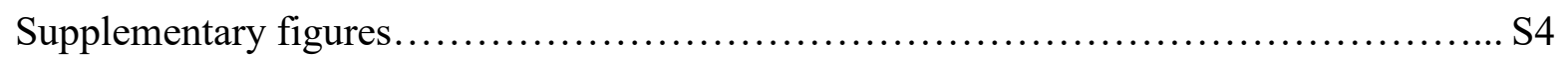

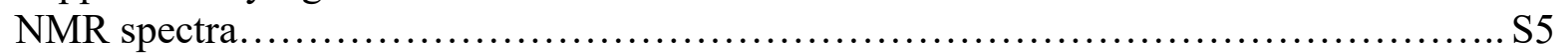

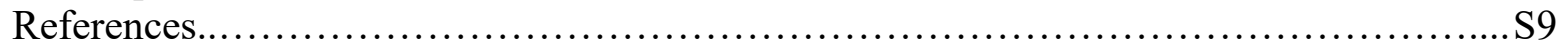

\section{Materials and Methods}

All chemicals are from Sigma-Aldrich-Merck, unless indicated otherwise.

Arg-Chi synthesis. The arginine-chitosan (Arg-Chi) synthesis protocol was adapted from Baker et al. ${ }^{1} 3 \mathrm{~g}$ chitosan (Heppe Medical Chitosan $\mathrm{GmbH}, 82.6$ - 87.5\% deacetylated, 80-200 kDa) were dissolved in $228 \mathrm{~mL}$ $0.1 \mathrm{M} \mathrm{HCl}$. Separately, $5.437 \mathrm{~g}(47.24 \mathrm{mmol}) \mathrm{N}$-hydroxysuccinimide (NHS) and $12.96 \mathrm{~g}$ (47.24 mmol) BOCArg-OH were dissolved in $240 \mathrm{~mL} \mathrm{mQ} \mathrm{H} 2 \mathrm{O}$. Subsequently, $9.075 \mathrm{~g}$ (47.34 mmol) 1-Ethyl-3-(3dimethylaminopropyl)carbodiimide hydrochloride (EDC, Fluorochem) were dissolved in $8.25 \mathrm{~mL} \mathrm{mQ} \mathrm{H}_{2} \mathrm{O}$ and added to the NHS/BOC-Arg-OH mixture, stirred for $1 \mathrm{~min}$ and added dropwise to the chitosan solution. The mixture was gently stirred overnight. $22 \mathrm{~g}(0.38 \mathrm{~mol}) \mathrm{NaCl}$ were added to the solution followed by dialysis against $\mathrm{mQ} \mathrm{H}_{2} \mathrm{O}$ for 3 days to yield a pure $\mathrm{BOC}$-arginine-chitosan solution followed by lyophilization. The BOC protection group of arginine was removed from the Arg-Chi polymer by addition of $10 \mathrm{~mL} 95 \%$ Trifluoroacetic acid (TFA, Thermo Fisher Scientific) to $200 \mathrm{mg}$ of lyophilized product and stirred for $3 \mathrm{~h}$ in a closed flask. TFA was subsequently evaporated by blowing nitrogen gas into the open flask while stirring. The dried sample was re-suspended in $20 \mathrm{~mL} \mathrm{mQ} \mathrm{H}_{2} \mathrm{O}$ containing $0.5 \mathrm{~g}(8.56 \mathrm{mmol}) \mathrm{NaCl}$ and dialyzed against $\mathrm{mQ} \mathrm{H}_{2} \mathrm{O}$ containing $0.01 \mathrm{M} \mathrm{NaCl}$ for one day, followed by dialysis with pure $\mathrm{mQ} \mathrm{H}_{2} \mathrm{O}$ for another day. The sample was lyophilized for storage and the degree of arginine conjugation was estimated by ${ }^{1} \mathrm{H}-\mathrm{NMR}$ analysis to be approximately 13 $18 \%$. In short, the degree of substitution (DS) was calculated based on the fact that for each successfully conjugated arginine, the 3 methyl protons of the acetyl group (peak around $2 \mathrm{ppm}$ ) correspond to 4 protons of two methylene groups of arginine (respectively around 1.65 and $1.85 \mathrm{ppm}$ ), using the equation below:

Where DA is the degree of deacetylation.

$$
D S=\frac{\int \operatorname{ArgCH} 2 \times 3}{\int G l c N A c C H 3 \times 4} \times(100-D A)
$$

VS-COOH synthesis. The synthesis of the heterodifunctional linker VS-COOH was adapted from Broguiere et $a .^{2} 28 \mu \mathrm{l}(0.19 \mathrm{mmol})$ 1,8-Diazabicyclo[5.4.0]undec-7-ene (DBU) and $560 \mu \mathrm{l}$ (5.58 mmol) divinyl sulfone (DVS) were added to $4 \mathrm{~mL}$ dimethylformamide (DMF, Thermo Fisher Scientific) and stirred on ice. $200 \mu \mathrm{l}(2.88$ mmol) thioglycolic acid were added dropwise to the solution. The mixture was stirred on ice for 30 min before diluting with $5 \mathrm{~mL}$ of $30 \mathrm{mM}$ aqueous $\mathrm{HCl}$. The solution was immediately purified by preparative HPLC (Agilent Prep-C18, $100 \AA$ pore size, $10 \mu \mathrm{m}$ particle size, 250x50 mm) using 5\% ACN in $\mathrm{H} 2 \mathrm{O}$ in the presence of 
$0.1 \%$ TFA for 10 min followed by a gradient of 5 to $90 \%$ acetonitrile over 20 min with an $80 \mathrm{~mL} / \mathrm{min}$ flow rate. The residual acetonitrile in the collected VS-COOH solution was removed using a rotary evaporator and the resulting pure product was lyophilized. The successful synthesis of the desired product was confirmed by ${ }^{1} \mathrm{H}$ NMR analysis.

Arg-Chi-VS synthesis. The Arg-Chi-VS synthesis protocol was adapted from Broguiere et al. ${ }^{3} 610 \mathrm{mg}$ of ArgChi were dissolved in $248.7 \mathrm{~mL}$ 2-morpholinoethanesulfonic acid solution (MES, pH 4.5, $150 \mathrm{mM}$ ). $684 \mathrm{mg}$ (3.25 mmol) VS-COOH were dissolved separately in $31 \mathrm{~mL}$ MES solution and added to the Arg-Chi solution. The $\mathrm{pH}$ was adjusted back to 4.5 by addition of aqueous $\mathrm{NaOH} .624 \mathrm{mg}(3.26 \mathrm{mmol})$ EDC were dissolved in $23.3 \mathrm{~mL} \mathrm{mQ} \mathrm{H}_{2} \mathrm{O}$ and added dropwise to the reaction mixture under vigorous stirring. The stirring was slowed down, and the reaction left to proceed for $2 \mathrm{~h}$. Subsequently, $217 \mathrm{mg}(1.13 \mathrm{mmol})$ EDC were dissolved in $8 \mathrm{~mL}$ $\mathrm{mQ} \mathrm{H}_{2} \mathrm{O}$ and added dropwise to the solution and the reaction was left to continue for another $2 \mathrm{~h}$. Then, $5 \mathrm{~g}$ (85.56 mmol) $\mathrm{NaCl}$ were added and the solution was dialyzed against $\mathrm{mQ} \mathrm{H}_{2} \mathrm{O}$ containing $20 \mathrm{mM} \mathrm{NaCl}$ for 3 days. After dialysis, the sample containing $20 \mathrm{mM} \mathrm{NaCl}$ was immediately used for the next synthesis step due to limited solubility after the freeze-drying procedure. A small amount of Arg-Chi-VS was lyophilized only for ${ }^{1} \mathrm{H}-$ NMR analysis. The degree of VS-COOH conjugation was determined by ${ }^{1} \mathrm{H}-\mathrm{NMR}$ to be approximately $11-16 \%$. In short, DS was calculated based on the fact that for each successfully conjugated vinyl sulfone (VS) moiety, the 3 vinyl sulfone protons (peaks around 6.4 and $6.9 \mathrm{ppm}$ ) correspond to the 3 methyl protons of the acetyl group (peak around $2 \mathrm{ppm}$ ), using the equation below:

$$
D S=\frac{\int \text { VSpeaks } \times 3}{\int G l c N A c C H 3 \times 3} \times(100-D A)
$$

Where DA is the degree of deacetylation.

Peptide synthesis. TG-Q (Ac-NQEQVSPL-ERCG-NH ${ }_{2}$ ) and TG-K (Ac-FKGG-ERCG-NH ${ }_{2}$ ) peptide synthesis was performed on Prelude ${ }^{\circledR} \mathrm{X}$ (Gyros Protein Technologies) by means of classical solid phase peptide synthesis (SPPS) with rink-amide resins and Fmoc-protected amino acids.

Arg-Chi-TG synthesis. The Arg-Chi-TG synthesis protocol was adapted from Broguiere et al. ${ }^{3}$ One part of ArgChi-VS was conjugated to the glutamine-providing peptide TG-Q and the other to the lysine-providing peptide TG-K, serving as substrates for transglutaminase mediated crosslinking. $1 \mathrm{~mL}$ TEOA buffer $(300 \mathrm{mM}, \mathrm{pH} 8)$ was added per $10 \mathrm{~mL}$ of Arg-Chi-VS solution. The solution was then split into two equal parts, sealed in a flask and deoxygenized by bubbling with nitrogen gas for $15 \mathrm{~min}$. TG-Q (864 mg, $0.64 \mathrm{mmol})$ and TG-K (576 mg, $0.64 \mathrm{mmol}$ ) were each dissolved in $15 \mathrm{~mL} \mathrm{mQ} \mathrm{H}_{2} \mathrm{O}$ and added to the sealed flasks which were then deoxygenized a second time. The reaction was left to proceed overnight at room temperature without stirring. $4 \mathrm{~g}$ $(68.45 \mathrm{mmol}) \mathrm{NaCl}$ were added to each flask and the solutions were dialyzed against $\mathrm{mQ} \mathrm{H}_{2} \mathrm{O}$ for 3 days with frequent $\mathrm{H}_{2} \mathrm{O}$ changes. The samples were subsequently lyophilized and complete conjugation of TG peptides was confirmed by the disappearance of the vinyl peaks on ${ }^{1} \mathrm{H}-\mathrm{NMR}$ spectra.

Zeta-potential analysis. Measurements were performed in triplicates at $25^{\circ} \mathrm{C}$ on ZetaSizer Nano ZS (Malvern Panalytical) with $5 \mathrm{mg} / \mathrm{mL}$ polymer solutions in $0.1 \mathrm{M} \mathrm{HCl}$ to ensure complete solubility of all tested materials.

General procedure for hydrogel preparation. Arg-Chi-TG-K and Arg-Chi-TG-Q were separately dissolved at $3 \%$ in Tris buffer (50 mM Tris, $50 \mathrm{mM} \mathrm{CaCl}$ and $100 \mathrm{mM} \mathrm{D-glucose)} \mathrm{and} \mathrm{pH}$ was adjusted to $7.1 \%$ and $2 \%$ polymer solutions were prepared by dilution of the 3\% stock with Tris buffer (pH 7). Arg-Chi-TG-K and ArgChi-TG-Q solutions were mixed together in equal amounts shortly before use. After addition of $2.5 \mu$ thrombin (500 U/mL, Baxter) and $5 \mu \mathrm{l} \mathrm{FXIII} \mathrm{(200} \mathrm{U/mL,} \mathrm{Fibrogammin,} \mathrm{CSL} \mathrm{Behring)} \mathrm{per} 92.5 \mu 1$ of Arg-Chi-TG solution, the mixture was quickly mixed by pipetting for a few seconds to ensure homogenous distribution of the enzymes before gelation onset.

Rheology. Gelation kinetics and shear-recovery hydrogel behavior were recorded on an Anton Paar MCR 301 rheometer equipped with a $20 \mathrm{~mm}$ parallel plate geometry. The gap was set to $0.2 \mathrm{~mm}$ and measurements were performed in a humidified chamber at $25^{\circ} \mathrm{C}$. After preparation of the hydrogels as described above, $76 \mu$ were immediately loaded onto the rheometer in order to start the measurement shortly after the addition of the enzymes. Both storage and loss modulus were measured in triplicates with oscillatory tests at a frequency of 1 $\mathrm{Hz}$ and $2 \%$ strain with 20 second measurement steps for a total of 1 hour. For the shear recovery test, hydrogels were prepared according to the same method and incubated for $30 \mathrm{~min}$ for completion of gelation. Storage and loss modulus were measured at $1 \mathrm{~Hz}$ for the hydrogels exposed to the following sequence of mechanical stress twice: $0.5 \%$ strain for $200 \mathrm{~s}, 500 \%$ strain for $10 \mathrm{~s}$ and $0.5 \%$ strain for $10 \mathrm{~min}$. 
Tensile test. Adhesion strength to cartilage tissue was measured through tensile testing using a texture analyzer (Stable Micro Systems, London, England). Bovine articular cartilage samples were obtained from a calf knee (36 months of age, Metzgerei Angst, Zürich). Cartilage samples of approximately 1-2 mm thickness were collected and cut into $4 \mathrm{~mm}$ diameter discs using biopsy punches (Kai Medical, Japan). A disc was attached to the lower sample holder with super glue. Arg-Chi-TG 3\% solution was prepared as described above, quickly mixed using a pipette and placed onto the cartilage disc surface. Rapidly, a second cartilage disc was placed on top of the gelling solution and pressed together until complete gelation. Super glue was then used to attach the upper sample holder to the top surface of the second cartilage disc. After $15 \mathrm{~min}$, the upper disc was pulled upward with a speed of $0.5 \mathrm{~mm} / \mathrm{s}$ until the two discs detached from each other. As controls, the same measurements were performed using $10 \mu \mathrm{L}$ of PBS or commercially available fibrin glue $(5 \mu \mathrm{L}$ component $\mathrm{A}+5 \mu \mathrm{L}$ component $\mathrm{B}$, Tisseel, Baxter, USA). Measurements were performed in triplicates.

Degradation test. $15 \mu \mathrm{l}$ of 3\% Arg-Chi-TG hydrogels $(n=3)$ were prepared according to the method described above. Each hydrogel was transferred to a pre-weighted Eppendorf tube filled with $0.2 \mathrm{~mL}$ PBS. After incubation of the hydrogels for 0,3 and 9 days, the tubes' contents were freeze-dried. The weights of the empty tubes and the tubes filled with dried gels were compared to calculate relative dry weight of hydrogels at each time point.

Cartilage infiltration. Cartilage discs of approximately 1-2 $\mathrm{mm}$ in thickness and $4 \mathrm{~mm}$ in diameter were obtained as described above. Cartilage defects were manually made with a scalpel. To visualize infiltration of Arg-Chi in articular cartilage, the polymer was labeled with Fluorescein 5(6)-isothiocyanate (FITC). In short, Arg-Chi was dissolved at $10 \mathrm{mg} / \mathrm{mL}$ in $\mathrm{mQ} \mathrm{H}_{2} \mathrm{O}$ and subsequently an equal dimethyl sulfoxide (DMSO) volume was added to the solution while stirring. FITC was separately dissolved at $0.47 \mathrm{mg} / \mathrm{mL}$ in DMSO and slowly added to the Arg-Chi solution at a 1:2 volume ratio. The reaction was left to proceed in the dark for $3 \mathrm{~h}$. Then, $\mathrm{NaCl}$ was added to $33 \mathrm{mg} / \mathrm{mL}$ final concentration and the solution was dialyzed against $\mathrm{mQ} \mathrm{H}_{2} \mathrm{O}$ for $24 \mathrm{~h}$ followed by lyophilization. Arg-Chi-FITC was dissolved in PBS $(10 \mathrm{mg} / \mathrm{mL})$ and the cartilage samples were incubated in this solution for 1, 5, 15, 30 and $60 \mathrm{~min}$ in the dark before washing with PBS 3 times for 3 min. Additionally, samples were incubated in the Arg-Chi-FITC solution for $60 \mathrm{~min}$ and subsequently incubated in PBS for 4 days to visualize retention within the cartilage tissue. After the washing steps, samples were cut in half to image their cross sections. Following the same incubation and washing steps, a solution of Fluorescein $77 \mu \mathrm{M}$ in PBS was used to study the infiltration and retention behavior of the dye only. All images were acquired at $5 \mathrm{x}$ magnification (Zeiss Axio Observer Z1) and processed with Zeiss Zen Light Edition.

Cartilage defect filling. Osteochondral grafts were obtained from a calf knee. Cartilage defect was manually made with a scalpel. Arg-Chi-TG 3\% solution was prepared as described above and quickly mixed with minimum amount of $40 \mathrm{kDa}$ TRITC-dextran to ensure better visualization of the polymer solution. The solution was pipetted into the defect. After 3 minutes, successful crosslinking was assessed by touching the hydrogel surface with a needle. Images and videos were acquired with Leica M80.

Assessment of antibacterial activity. Staphylococcus aureus ATCC 6538 were cultured in 5 mL of Tryptic Soy Broth (TSB) at $37^{\circ} \mathrm{C}$ and $160 \mathrm{rpm}$ overnight. The cultures were then diluted to $10^{6}$ colony-forming units (CFU)/mL, of which $200 \mu 1$ were plated onto PC-Agar plates. Samples Arg-Chi and Arg-Chi-TG were dissolved in PBS to $2 \mathrm{mg} / \mathrm{mL}$. $5 \mu \mathrm{L}$ drops of the polymer solution were loaded on the prepared bacterial agar plates. The plates were incubated overnight at $37{ }^{\circ} \mathrm{C}$ prior to imaging. All samples were tested in at least triplicate for each condition.

MTS assay. Bovine articular chondrocytes (passage 3) were seeded into 96-well plates at 10'000 cells per well and incubated at $37^{\circ} \mathrm{C}$ in DMEM (Gibco) containing $10 \%$ fetal bovine serum (Gibco), gentamycin $(10 \mu \mathrm{g} / \mathrm{ml}$, Gibco) and FGF2 (50 ng/ml, Peprotech) for $24 \mathrm{~h}$. Separately, 2\% Arg-Chi-TG hydrogels were cast into polydimethylsiloxane (PDMS) rings (1 mm height, $4 \mathrm{~mm}$ inner diameter), incubated for 30 min for complete gelation, washed with cell medium, and followed by incubation for $24 \mathrm{~h}$ in the medium described above $(1 \mathrm{~mL}$ per sample). After $24 \mathrm{~h}$ in culture, the cell medium of the chondrocytes was replaced by the medium incubated with the hydrogels as well as with solutions of non-crosslinked Arg-Chi and Arg-Chi-TGQ/K (1:1 mix) dissolved in the medium described above at 0.1 and $0.5 \mathrm{mg} / \mathrm{mL}$. The cells were incubated for $72 \mathrm{~h} .10 \mu 1$ MTS reagent (Abcam) were added per well and incubated at $37^{\circ} \mathrm{C}$ for $40 \mathrm{~min}$. Absorbance was measured at $490 \mathrm{~nm}$ (Synergy H1 Hybrid Reader, BioTek) and blank (sample medium only) values for each sample set were subtracted from the measured values of wells containing cells and samples. The assay was performed in triplicates (100 $\mu \mathrm{l} /$ well). 


\section{Supplementary Figures}

\begin{tabular}{|c|c|c|c|}
\hline & $\begin{array}{c}\text { Zeta Potential } \\
{[\mathrm{mV}]}\end{array}$ & $\begin{array}{c}\text { Conductivity } \\
{[\mathrm{mS} / \mathrm{cm}]}\end{array}$ & $\begin{array}{c}\text { Mobility } \\
{[\mu \mathrm{m} \mathrm{cm} / \mathrm{V} \mathrm{s}]}\end{array}$ \\
\hline Chitosan & $38.4 \pm 3.1$ & $39.5 \pm 0.3$ & $3.007 \pm 0.244$ \\
\hline Arg-Chi & $31.3 \pm 1.6$ & $45.3 \pm 0.2$ & $2.458 \pm 0.125$ \\
\hline Arg-Chi-TGQ & $21.7 \pm 0.3$ & $44.8 \pm 0.4$ & $1.703 \pm 0.027$ \\
\hline Arg-Chi-TGK & $25.0 \pm 0.4$ & $45.1 \pm 0.1$ & $1.958 \pm 0.035$ \\
\hline
\end{tabular}

Table S1. Zeta-potential measurements of chitosan and chitosan derivatives showing retention of positive charges upon polymer functionalization $(n=3)$.

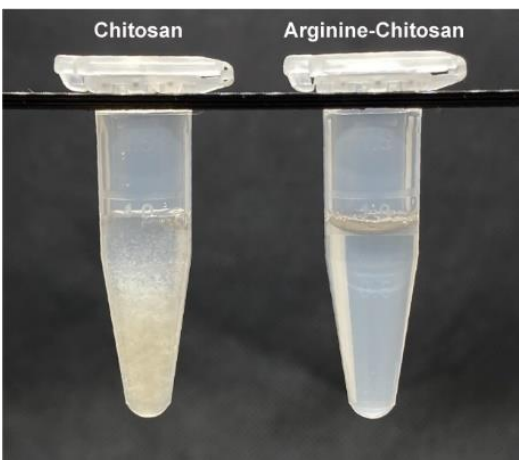

Figure S1. Solubility of chitosan and arginine-chitosan (Arg-Chi). Unmodified chitosan (left) is not soluble in PBS at neutral $\mathrm{pH}$ and forms clear precipitates. In contrast, Arg-Chi (right) is nicely soluble at neutral $\mathrm{pH}$, resulting in a clear solution with no precipitation.
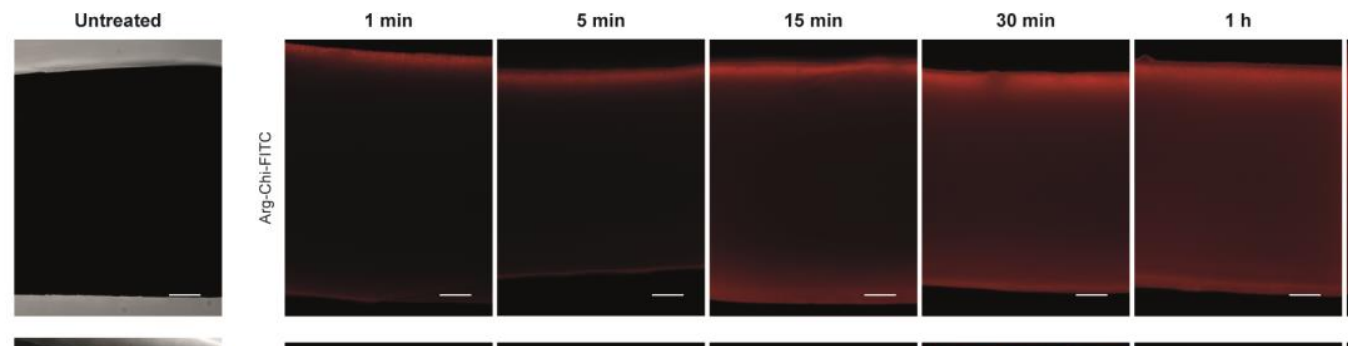

$4 \mathrm{~d}$ retention
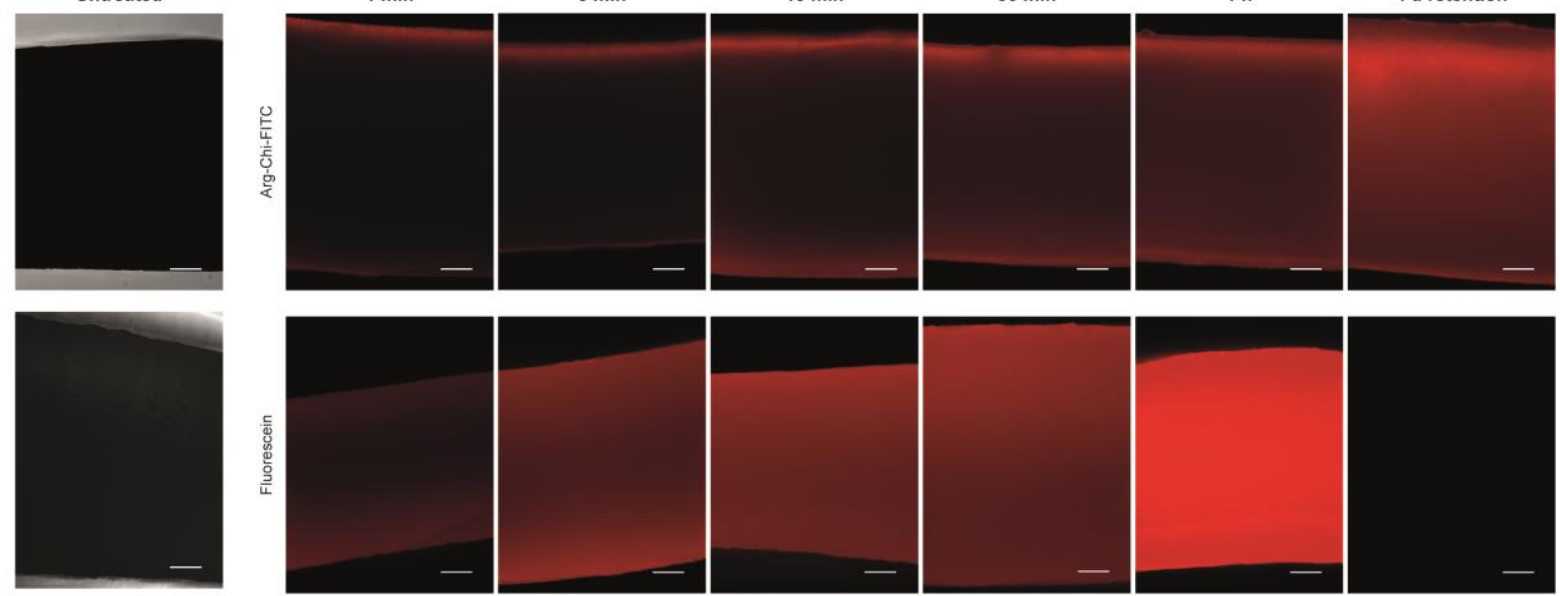

Figure S2. Infiltration test. Comparison of Arg-Chi-FITC and Fluorescein infiltration and retention in bovine cartilage samples. Complete cross-section imaging (scale bar, $200 \mu \mathrm{m}$ ). 


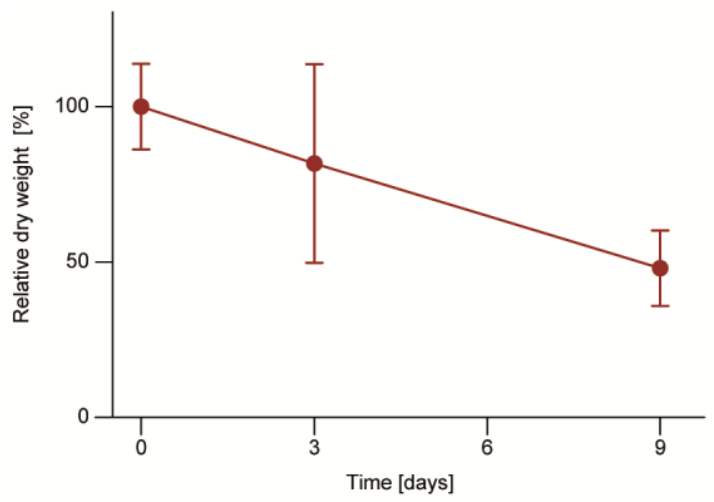

Figure S3. Degradation of Arg-Chi-TG hydrogels $(n=3)$. Relative dry weight of the hydrogels incubated at 37 ${ }^{\circ} \mathrm{C}$ for 0,3 and 9 days in PBS solution.

\section{NMR spectra}

NMR spectra were acquired on Bruker Ultrashield 400MHz or Bruker Ascend 500MHz.

\section{VS-COOH}

${ }^{1} \mathrm{H}$ NMR (500 MHz, $\mathrm{D}_{2} \mathrm{O}$ )<smiles>C=CS(=O)(=O)SCSSC(=O)O</smiles>

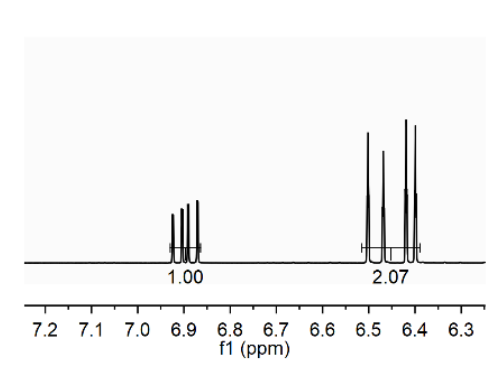

HOD

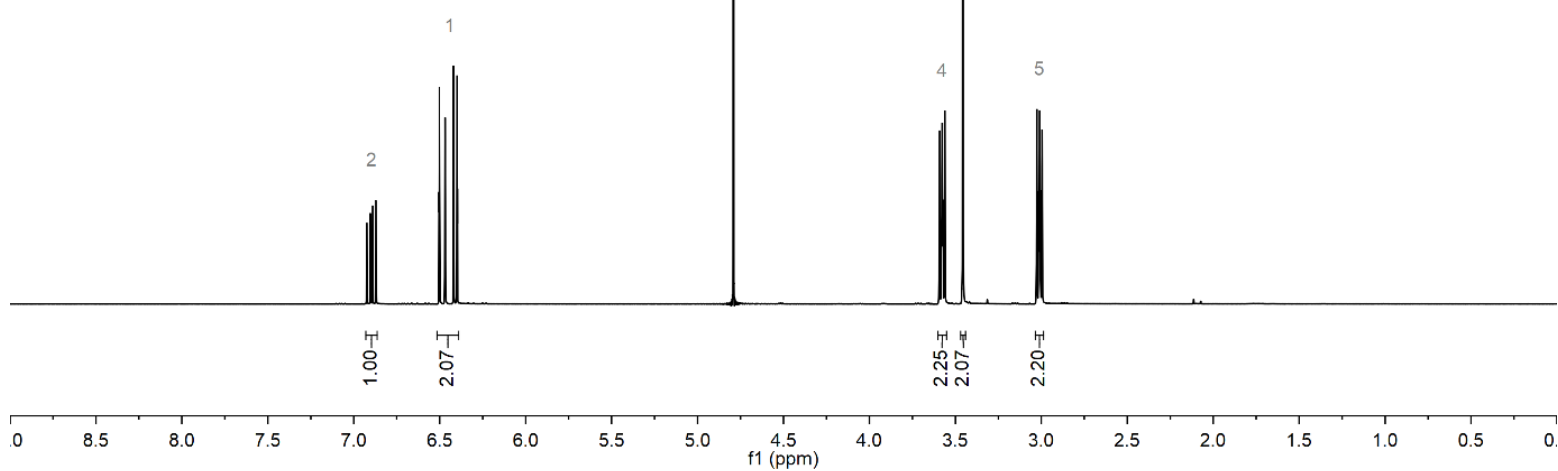




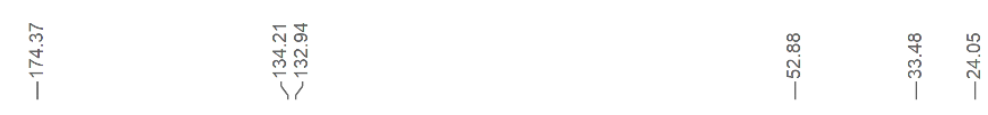

${ }^{13} \mathrm{C}$ NMR (126 MHz, $\left.\mathrm{D}_{2} \mathrm{O}\right)$

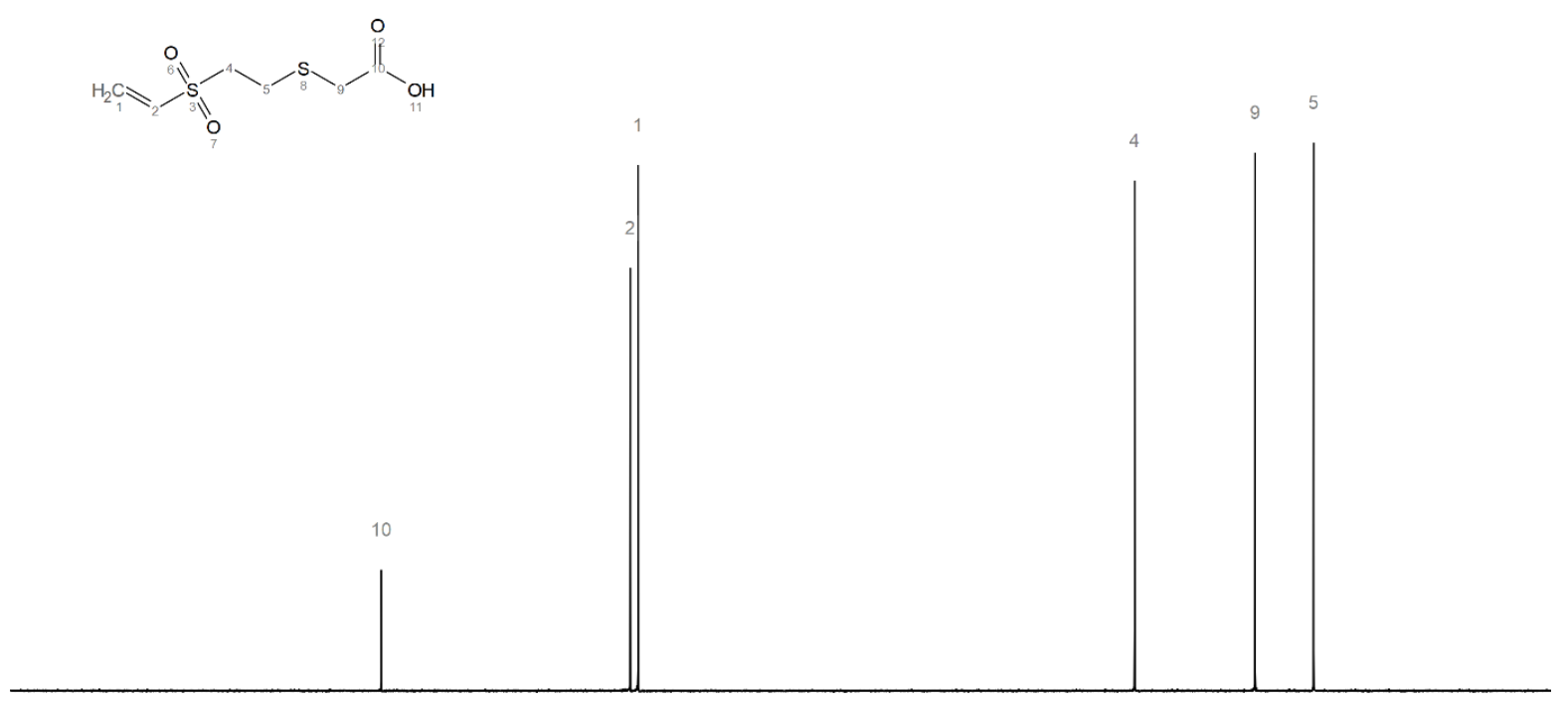

\begin{tabular}{llllllllllllllllllllllllllllllllll}
\hline 230 & 220 & 210 & 200 & 190 & 180 & 170 & 160 & 150 & 140 & 130 & 120 & 110 & 100 & 90 & 80 & 70 & 60 & 50 & 40 & 30 & 20 & 10 & 0 & -10
\end{tabular}

\section{Arg-Boc-Chi}

'H NMR (400 MHz, $\mathrm{D}_{2} \mathrm{O}$ )

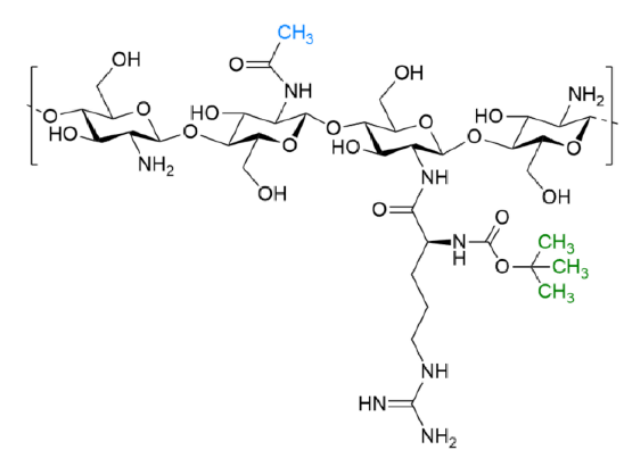

HOD

$\begin{array}{lllllllllllllllllllllllll}.0 & 10.5 & 10.0 & 9.5 & 9.0 & 8.5 & 8.0 & 7.5 & 7.0 & 6.5 & 6.0 & 5.5 & 5.0 & 4.5 & 4.0 & 3.5 & 3.0 & 2.5 & 2.0 & 1.5 & 1.0 & 0.5 & 0.0 & -0.5\end{array}$ 


\section{Arg-Chi}

${ }^{1} \mathrm{H}$ NMR (500 MHz, $\left.\mathrm{D}_{2} \mathrm{O}\right)$

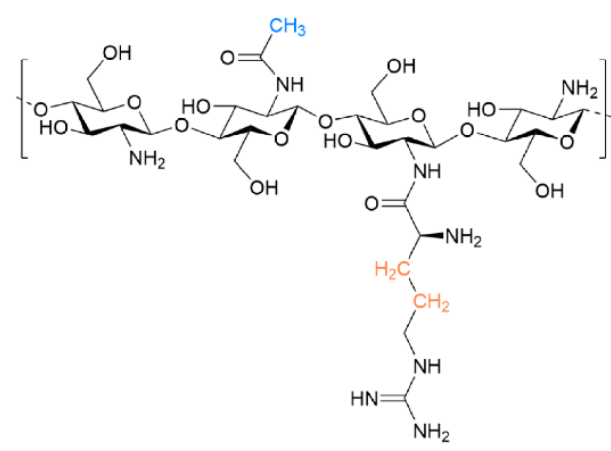

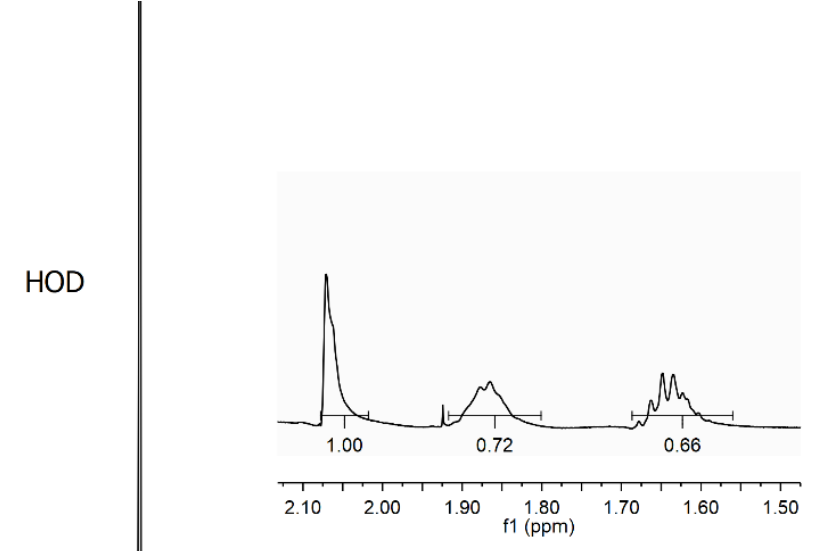

10

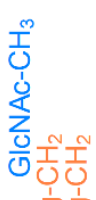

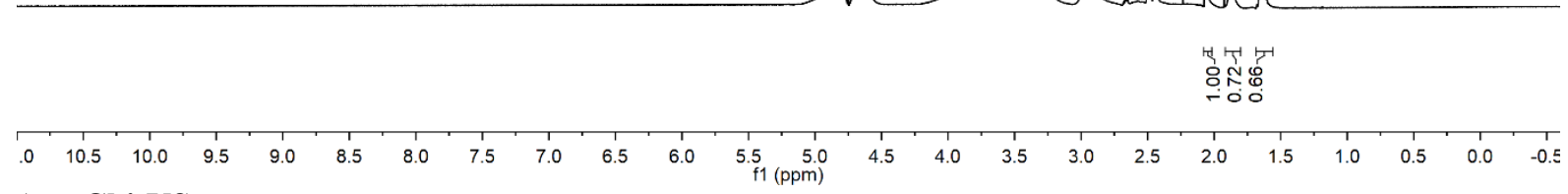
Arg-Chi-VS

${ }^{1} \mathrm{H}$ NMR (400 MHz, $\mathrm{D}_{2} \mathrm{O}$ )
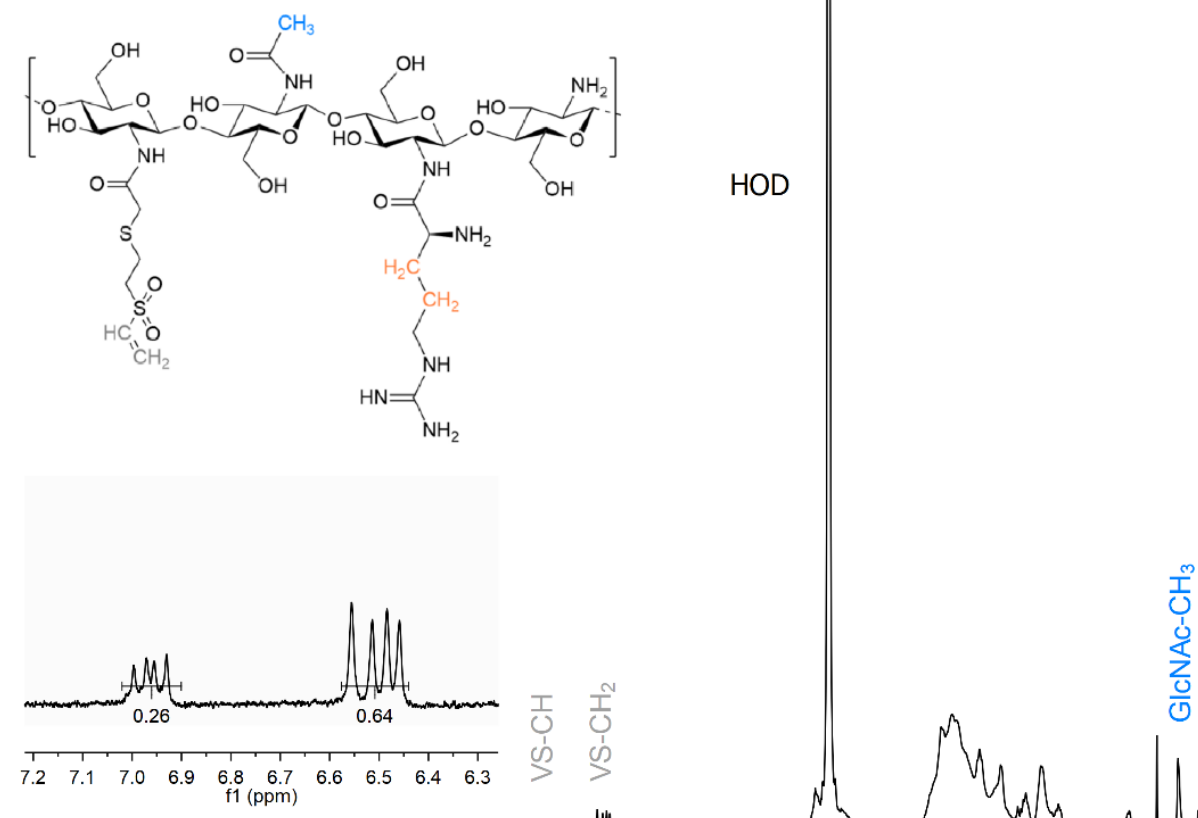

i

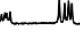

Y.

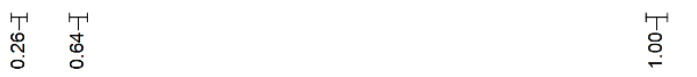

$\begin{array}{llllllllllll}1.0 & 10.5 & 10.0 & 9.5 & 9.0 & 8.5 & 8.0 & 7.5 & 7.0 & 6.5 & 6.0 & 5.5 \\ \mathrm{f} 1(\mathrm{ppm})\end{array}$ 


\section{Arg-Chi-VS and Arg-Chi-TGK}
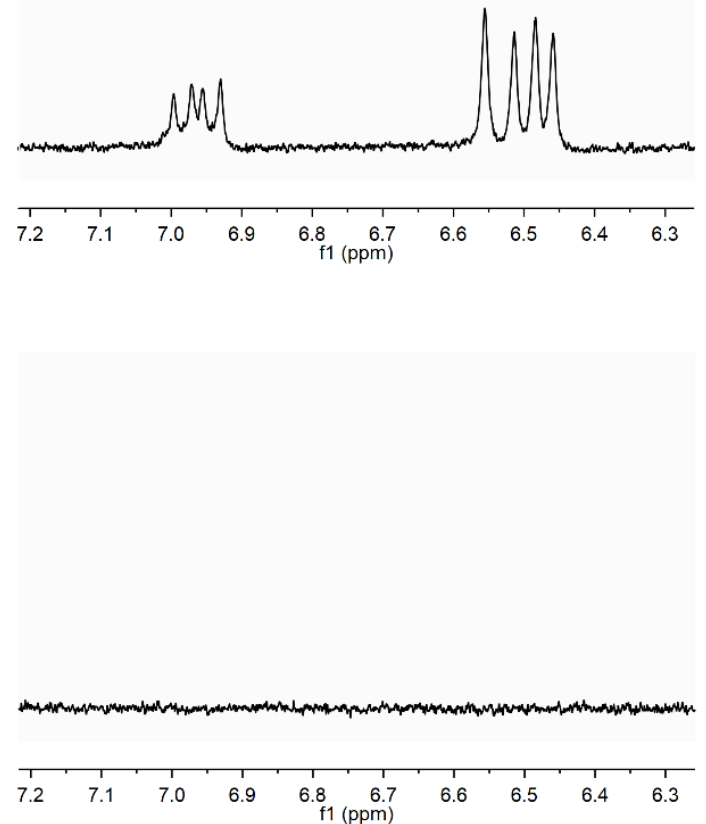

\section{Arg-Chi-VS and Arg-Chi-TGQ}
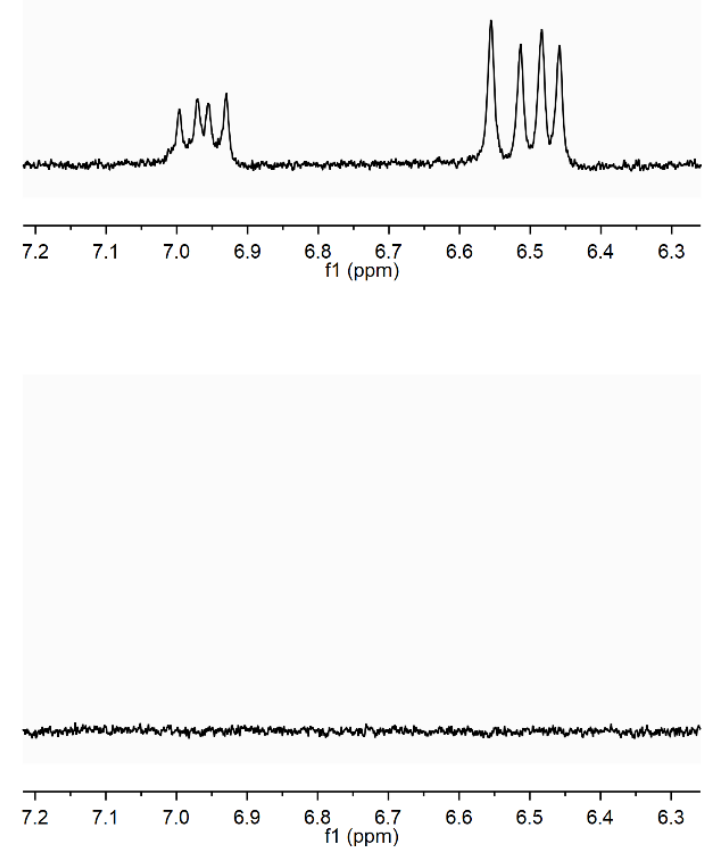

${ }^{1} \mathrm{H} \mathrm{NMR}\left(400 \mathrm{MHz}, \mathrm{D}_{2} \mathrm{O}\right)$ Arg-Chi-VS

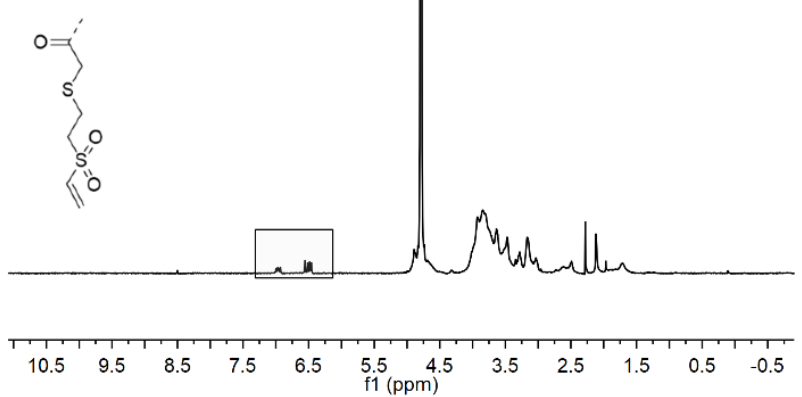

${ }^{1} \mathrm{H}$ NMR (400 MHz, D $2 \mathrm{O}$ )

Arg-Chi-TGK

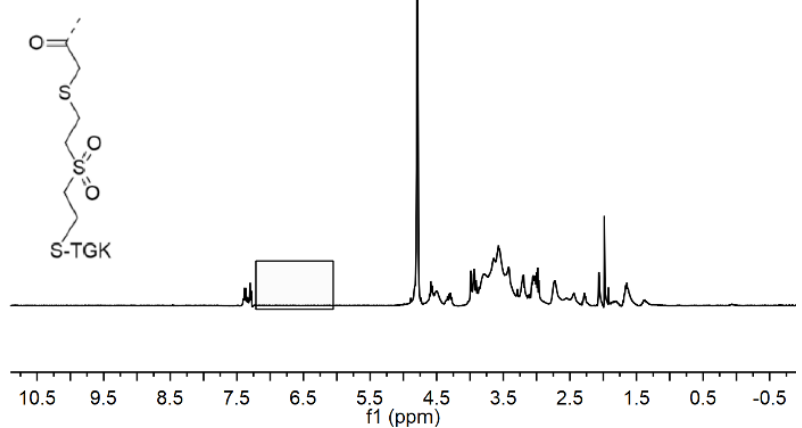

$\mathrm{H}$ NMR $\left(400 \mathrm{MHz}, \mathrm{D}_{2} \mathrm{O}\right)$ Arg-Chi-VS

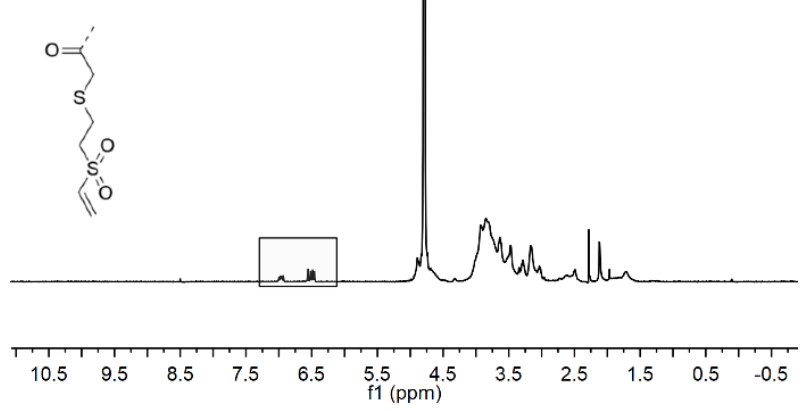

${ }^{1} \mathrm{H}$ NMR (400 MHz, D $2 \mathrm{O}$ ) Arg-Chi-TGQ

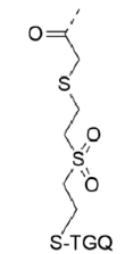
wholumbar

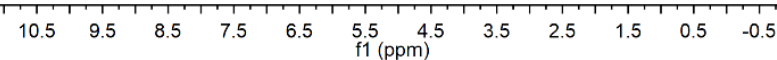




\section{References}

1. Baker, S.; Wiesmann, W. P.; Ryan, S. Chitosan-derivative compounds and methods of controlling microbial populations. U.S. Patent 8,119,780, Feb 21, 2012.

2. $\quad$ Broguiere, N.; Lüchtefeld, I.; Trachsel, L.; Mazunin, D.; Rizzo, R.; Bode, J. W.; Lutolf, M. P.; Zenobi-Wong, M., Morphogenesis Guided by 3D Patterning of Growth Factors in Biological Matrices. Adv. Mater. 2020, 32, 1908299.

3. Broguiere, N.; Isenmann, L.; Zenobi-Wong, M., Novel Enzymatically Cross-Linked Hyaluronan Hydrogels Support the Formation of 3D Neuronal Networks. Biomaterials 2016, 99, 47-55. 